\title{
Synthesis, characterization and anticancer activity of rutin loaded chitosan nanoparticles
}

\author{
M.D. Imad Uddin , K. Saivani, K.V. Akhil, K. Nandini, K. Sandhya and Faizan Sayeed* \\ Department of Pharmacology, Pulla Reddy Institute of Pharmacy, Hyderabad-502313, T.S., India \\ *Department of Pharmaceutics, Mesco College of Pharmacy, Hyderabad-500006, T.S., India
}

\begin{tabular}{|c|c|}
\hline Article Info & Abstract \\
\hline $\begin{array}{l}\text { Article history } \\
\text { Received } 1 \text { February } 2021 \\
\text { Revised } 17 \text { March } 2021 \\
\text { Accepted } 19 \text { March } 2021 \\
\text { Published Online } 30 \text { March } 2021\end{array}$ & $\begin{array}{l}\text { Rutin is one of the well-known phytoconstituent with antioxidant property and also exhibiting anti- } \\
\text { cancer potential. In this study, ionic gelation method is followed to prepare chitosan nanoparticles } \\
\text { loaded with rutin (RCNPs). These nanoparticles are characterized by different techniques like fourier } \\
\text { transform infrared spectroscopy (FTIR) for identifying functional groups, Zeta potential for assessing } \\
\text { stability, X-ray diffraction spectroscopy (XRD) for determining structure, and scanning electron micros- } \\
\text { copy (SEM) for identifying surface morphology. FTIR spectra of RCNPs showed the presence of different }\end{array}$ \\
\hline $\begin{array}{l}\text { Keywords } \\
\text { Rutin } \\
\text { Nanoparticles } \\
\text { Chitosan } \\
\text { Anti cancer activity } \\
\text { Ovarian cancer }\end{array}$ & $\begin{array}{l}\text { functional groups of chitosan and also the peaks corresponding to functional group of rutin, indicating } \\
\text { successful encapsulation of rutin in chitosan nanoparticles. Debye-Scherrer equation was applied for } \\
\text { XRD data and RCNPs size was found to be } 32.15 \mathrm{~nm} \text {. SEM image revealed the porous and rough } \\
\text { morphology of the surface of RCNPs. Zeta potential was found to be }+0.68 \mathrm{mV} \text {, indicating stability of } \\
\text { nanoparticles. Entrapment efficiencies (EE \%) was found to be } 68.7 \% \text {, Loading efficiencies (LE \%) was } \\
\text { found to be } 50.8 \% \text {, \% yield of RCNPs was found to be } 31.08 \% \text {. Based on the above test values, RCNPs } \\
\text { were further subjected to anti-proliferative activity by MTT assay on various cancer cell like HeLa } \\
\text { (Cervical cancer cells), PC } 3 \text { (Prostate cancer cells), MDAMB231 (Breast cancer cells), Panc-1 (Pancre- } \\
\text { atic cancer cells), SK0V3 (Ovarian cancer cells). The results showed that rutin and RCNPs have anti- } \\
\text { proliferative effect on SK0V3 cell line only and effects of RCNPs were greater when compared to that } \\
\text { of pure rutin. On this basis, we can suggest that rutin loaded chitosan nanoparticles have promising } \\
\text { therapeutic role in cancer treatment. }\end{array}$ \\
\hline
\end{tabular}

\section{Introduction}

Globally, cancer is a second principal reason of fatality and includes 277 various types (Hassanpour and Dehghani, 2017). Cancer cells are characterized by abnormal growth and uncontrolled division (Balachandran and Govindarajan, 2005). Main treatment option is chemotherapy, surgery, radiotherapy, and hormone therapy (Shihabul et al., 2018). Alopecia, anemia, exhaustion, and nausea are the major side effects. Moreover, therapeutic application of above said options was also decreased due to high toxicity, high cost, and low efficacy (Shaûei et al., 2015). In this context, scientists all over the world are focusing on plant based therapies. Considering the significance of all phytoconstituents, in particular flavonoids play a vital role in management of life threatening diseases. A flavonoid 7-methyl gallic acid has a role in treatment of neurodegenerative related disorders (Pugazhendhi et al., 2018). Other flavonoids such as rutin, vinca alkaloids, etoposides, etc., are used in the treatment and management of cancer, as compounds derived from plants are more tolerant, non-toxic to normal human cells (Mariyappan et al., 2018). Majority of flavonoids are polar compounds and water soluble in nature which limits their

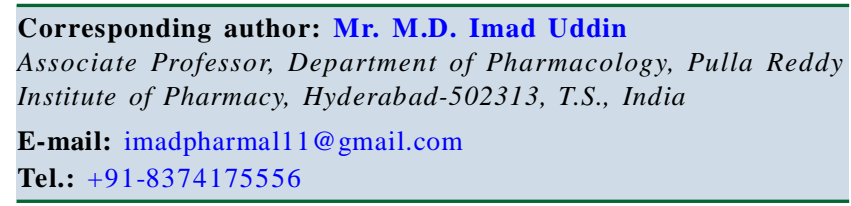

Copyright () 2021 Ukaaz Publications. All rights reserved.

Email: ukaaz@yahoo.com; Website: www.ukaazpublications.com absorption. Two are the important factors which decrease their bioavailability, first factor is molecular size which blocks their passive absorption and second factor is weak lipid solubility which restricts their entry through phospholipid layer. Hence, there is a challenge to increase bioavailability of these flavonoids, in order to increase their therapeutic efficacy (Khan et al., 2013; Li et al., 2015; Sepahvand et al., 2014).

Rutin is also known as quercetin-3-rutinoside (Mauludin et al., 2009) which is commonly found in tea, passion flower, apple, and buckwheat (Harborne, 1986). It is reported with many pharmacological activities, viz., cardioprotective (Annapurna et al., 2009), neuroprotective (Pu et al., 2007), anticonvulsant activity (Nieoczym et al., 2014), antidepressant effects (Machado et al., 2008), analgesic (Rylski et al., 1979), antinociceptive effects (Selvaraj et al., 2014), and anticancer effects (Alonso-Castro et al., 2013). It is reported to possess anticancer potential against HL-60 human leukemia cells (Lin et al., 2012), LAN-5 human neuroblastoma cells (Chen et al., 2013), colorectal cell (Araujo et al., 2011), OVCA 433 ovarian cancer cells (Scambia et al., 1990) and pancreatic cancer cells (Mouria et al., 2002).

Taking in to consideration of different pharmacological activities of rutin and its action profile against cancer cells many studies are conducted to increase its clinical use by increasing its bioavailability (Imad Uddin et al., 2020). Rutin loaded nanophytosomes was prepared with better antioxidant potential and bioavailability (Hooresfand et al., 2015). Targeted delivery to brain for treating 
cerebral ischemia was reported with rutin loaded chitosan nanoparticles (Ahmad et al., 2016). Chitosan nano formulations reported a key role in increasing bioavailability of many plant derived drugs. This is a polymer obtained by the de-acetylation (Ravi Kumar, 2001) of chitin which is a fibrous substance present in crab's exoskeleton, scales of fish, and cell walls of fungi (Shu and Zhu, 2002). Majority of biomedical uses of this polymer is due to its non-toxic, biodegradable, mucoadhesive, and biocompatible applications (Shanmuganathan et al., 2019). Moreover, it has the ability to attach to mucosal layer and fleetingly opens epithelial tight junctions (Qian et al., 2006). Based on above discussion, present work was designed to encapsulate rutin in chitosan to increase its therapeutic efficacy by improving its bioavailability.

\section{Materials and Methods}

\subsection{Materials}

\subsubsection{Chemicals and cell lines}

Sodium tripolyphosphate (STTP) (Qualikems Fine Chemical Limited), ethanol, rutin (NR Chemicals). Chitosan with $\mathrm{MW}=68$ $\mathrm{kDa}$ and deacetylaton degree $=90 \%$ From Chemsworth Suppliers Pvt. Ltd., acetic acid, sodium hydroxide, DMSO (S.D. Fine Chemical Limited). HeLa, MDAMB231, PC3, SKOV3, Panc-1cell lines, Roswell Park Memorial Institute (RPMI), 3-(4,5-dimethyl-2-yl)2,5-diphynyltetrazoliumbromide (MTT), fetal bovine serum (FBS), Dulbecco's modified Eagle's medium (DMEM) are obtained from American type culture collection, United States. Sodium pyruvate, bovine insulin is procured from Sigma Aldrich.

\subsubsection{Equipments and Instruments}

Sensitive weighing balance (Citizen scale-CY220; India), pH Meter (Digisun Electronics-India), Sonicator (Citizen scale-CUD25; India), Magnetic stirrer (REMI-1MLH; India), Rapid cooling centrifuge (Remilabworld-CM12; India), Refrigerator (Whirlpool-DC20045; India), Hot air oven (Lab care-TC344; India), UV spectrophotometer (LabIndia-T60; India), Multimode plate reader (Perkin ElmerHH35000500; USA). FTIR (BRUKER-ALPHA; USA), XRD (SCHIMADZU-XRD7000; Japan), Zeta potential (MALVERNMAL1004428; United Kingdom), SEM (Hitachi-3000N; Japan).

\subsection{Methods}

\subsubsection{Synthesis of RCNP's}

$1 \mathrm{mg} / \mathrm{ml}$ chitosan solution of $\mathrm{pH} 5.0$ (adjusted with $\mathrm{NaOH}(0.1 \mathrm{M}$ conc)) was prepared by using $1 \% \mathrm{CH}_{3} \mathrm{COOH} .1 \mathrm{mg} / \mathrm{ml}$ STTP solution of $\mathrm{pH} 5.0$ was prepared by using double distilled water (DDW). 17.5 $\mathrm{ml}$ of chitosan solution containing rutin $(4 \mathrm{mg} / \mathrm{ml})$ was kept in a volumetric flask on a magnetic stirrer with a speed of $200 \mathrm{rpm}$ at room temp. To this solution, $9 \mathrm{ml}$ of above made STTP solution was added drop-by-drop. Above solution is kept on overnight stirring for the formation of nanoparticles. After $24 \mathrm{~h}$, solution is subjected for centrifugation at $8000 \mathrm{rpm}$ at $4^{\circ} \mathrm{C}$ for $20 \mathrm{~min}$. RCNPs are deposited at the base of centrifugation tube as a pellet which was washed thrice with $10 \%$ aqueous ethanol. Finally, pellet was stored at $4^{0} \mathrm{C}$ after resuspending in 10\% aqueous ethanol (Patil et al., 2010).

\subsubsection{EE \%, LE \% and \% yield of RCNP's}

$3 \mathrm{mg}$ of synthesized RCNP's was dissolved in $10 \%$ DDW and sonicated for $10 \mathrm{~min}$ at amplitude of $40 \%$. Above solution is centrifuged for $15 \mathrm{~min}$ at a speed of $3000 \mathrm{rpm}$ and at a temp. of $4^{\circ} \mathrm{C}$. Amount of rutin released from RCNPs in supernatant was estimated by measuring absorption at $354 \mathrm{~nm}$ by using UV visible spectroscope. Standard curve of pure rutin was obtained by taking absorbance of different concentrations of rutin, viz., 100, 200, 300, 400 and 500 $\mu \mathrm{g} / \mathrm{ml}$ at $354 \mathrm{~nm}$ by using UV visible spectroscope (Anitha et al., 2011).

$$
\begin{aligned}
& \mathrm{EE} \%=\left(\frac{\text { Total amount of rutin with in the pellet }}{\text { Intial amount of rutin for loading studies }}\right) \times 100 \\
& \mathrm{LE} \%=\left(\frac{\text { Total amount of rutin trapped with in the pellet }}{\text { Yield of RCNP's }}\right) \times 100 \\
& \% \text { Yield }=(\mathrm{W} 1 / \mathrm{W} 2) 100
\end{aligned}
$$

where W1 = Dried wt. of RCNPs; W2 = Wt. of Rutin + Wt. of STTP + Wt. of chitosan. (Sharma and Garg, 2010)

\subsubsection{Fourier transform infrared spectroscopy of RCNP's}

RCNP's are analyzed from 4000 to $500 \mathrm{~cm}^{-1}$ in FTIR spectroscopy. For FTIR mediated assessment, obtained RCNP's are diluted in DDW. To remove unbound moieties, these are centrifuged for 15 min at the speed of $5000 \mathrm{rpm}$. After discarding supernatant, pellet is suspended in DDW. To obtain pure product, above discussed procedure is repeated for 3 times. Finally to obtain a pure form of RCNP's, pellet is dried in hot air oven $\left(60^{\circ} \mathrm{C}\right)$. This is subjected to analysis (Kiran et al., 2010).

\subsubsection{X-Ray diffraction mediated assessment of RCNPs}

Crystallographic structural pattern of RCNPs was determined by using XRD. Instrument is maintained at $31 \mathrm{~mA}$ and $42 \mathrm{kV}$ voltage. 2-Theta scale was set from $2.0000^{\circ}$ to $50.0014^{\circ}$, Step $=0.0053^{\circ}$, step time $=13.93$ with Anode $\mathrm{Cu}$, wavelength- 1.5406 (Thomas $e t$ $a l ., 2009)$. Size of RCNP's was measured by applying the DebyeScherrer formula (Wang, 2000).

$$
\mathrm{D}=\frac{\mathrm{k} \lambda}{\beta \cos \theta}
$$

where, $\mathrm{D}=$ Average size of RCNP's , $\gamma=\mathrm{x}$-ray wavelength (1.5406), $\theta=$ Bragg's angle in degrees, $\beta=$ Full width at half the maximum (FWHM), $\mathrm{k}=$ constant $(0.94)$.

\subsubsection{Scanning electron microscopic analysis of RCNP's}

SEM is used to analyze morphology, size and shape of RCNP's. For preparation of sample, copper grid coated with copper is used. Small quantity of RCNP's was added to this grid. Extra solution was removed by using blotting paper. Finally, grid was subjected to analysis (Imad Uddin et al., 2018).

\subsubsection{Zeta potential measurement of RCNP's}

Stability of RCNP's was measured by using a common light scattering method. Whole experiment was conducted at room temperature. Analysis was carried out by using zeta potential analyzer (Dodane and Vilivalam, 1998).

\subsubsection{Anti-proliferative activity of RCNPs by MTT Assay}

Dulbecco's modified Eagle's medium and $5 \% \mathrm{CO}_{2}$ was used to grow four different cell lines, viz., MDAMB231, SKOV3, Panc-1 and HeLa. 10\% FBS is also added to DMEM. Experiment was conducted at $37^{\circ} \mathrm{C}$. RPMI medium containing non-essential amino acids, $10 \%$ FBS, $10 \mathrm{mg} / \mathrm{ml}$ bovine insulin and $1 \mathrm{mM}$ sodium pyruvate was used to grow PC3 cells. 
$100 \mu \mathrm{l}$ aliquots of trypsinized cells were prepared. Prepared aliquots were added to a 96-well microtiter plates. These plates were incubated for $24 \mathrm{~h}$ in atmospheric conditions like $100 \%$ relative humidity, 5\% $\mathrm{CO}_{2}$, temp. of $37^{\circ} \mathrm{C}$ and $95 \%$ of air. After $24 \mathrm{~h}$, rutin and RCNPs was added to each cell line at a conc. of $50 \mu \mathrm{M}$ and was incubated for more 48 h. $10 \mu \mathrm{l}$ of MTT $(5 \%)$ was added to stop the reaction. This is incuba-ted for $60 \mathrm{~min}$ at $37^{\circ} \mathrm{C}$. Air dried plates are eluted with DMSO $(100 \mu \mathrm{l})$ and used to record absorbance at $560 \mathrm{~nm}$ on a multimode plate reader (Imad Uddin et al., 2019).

\section{Results}

\subsection{Characterization of RCNPs}

Standard curve of rutin was obtained and $\mathrm{R}^{2}$ value was found to be 0.999 (Figure 1). For screening nanocarrier property of chitosan $\mathrm{EE} \%$ and $\mathrm{LE} \%$ are estimated which were found to be $68.7 \%$ and $50.8 \%$, respectively. FTIR analysis of chitosan nanoparticles are shown in Figure 2. $-\mathrm{OH}$ stretching vibration is indicated by peak at $3273.96 \mathrm{~cm}^{-1}, 1635.50 \mathrm{~cm}^{-1}$ indicates interaction between STTP and chitosan, $1539 \mathrm{~cm}^{-1}$ indicates $-\mathrm{NH}$ bending vibration of primary amine, C-O stretching is represented by peak at $1152.65 \mathrm{~cm}^{-1}$, $1070.51 \mathrm{~cm}^{-1}$ and $1023.50 \mathrm{~cm}^{-1}$ indicates -CO vibrations. In case of RCNPs (Figure 3), $3341 \mathrm{~cm}^{-1}$ and $1650.50 \mathrm{~cm}^{-1}$ indicates $-\mathrm{OH}$ stretching vibration and $\mathrm{C}=\mathrm{O}$ stretching vibrations, respectively. $\mathrm{C}$ $\mathrm{O}-\mathrm{C}$ vibrations, $\mathrm{P}=\mathrm{O}$ vibrations and $\mathrm{C}=\mathrm{C}$ vibrations are indicated by peaks at $1060 \mathrm{~cm}^{-1}, 1203 \mathrm{~cm}^{-1}$, and $1454 \mathrm{~cm}^{-1}$, respectively.

Physical nature of RCNPs was assessed by XRD technique and XRD-diffractogram is presented in Figure 4. $2 \theta$ peaks of RCNPs were found to be from 5.210 to 46.150 with intensity (cps) from 44.9 to 8.7. SEM image (Figure 5), revealed rough and porous surface of RCNPs. Stability of nano formulations is estimated by measuring potential on either surface or interface of particles. Irrespective of the charge particles with higher zeta potential are stable but the particles with lower value are unstable and are prone to flocculate. Zeta potential of RCNP (Figure 6) was found to be $+0.68 \mathrm{mV}$ which indicates low stability.

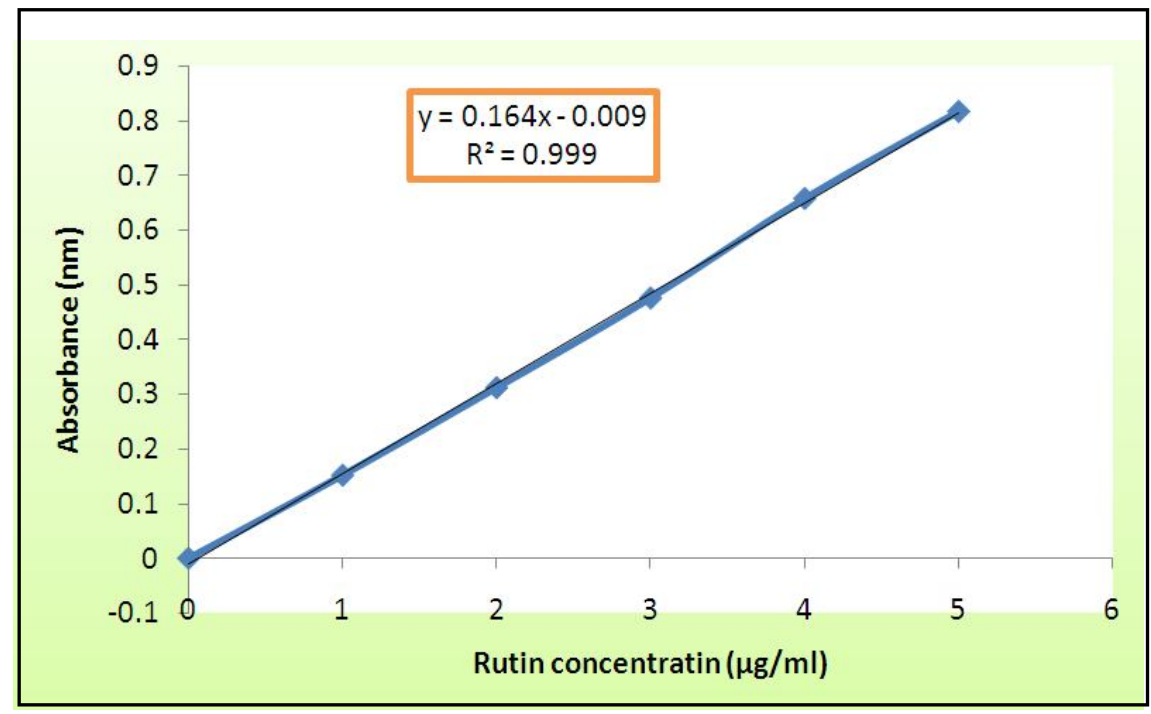

Figure 1: Standard curve of pure rutin.

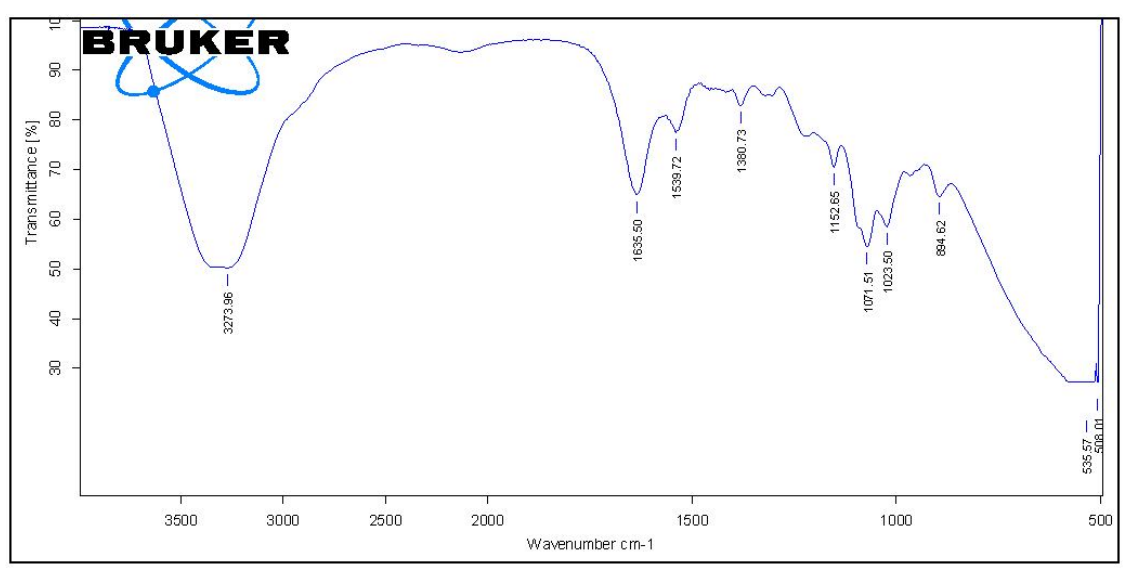

Figure 2: FTIR analysis of chitosan nanoparticle. 


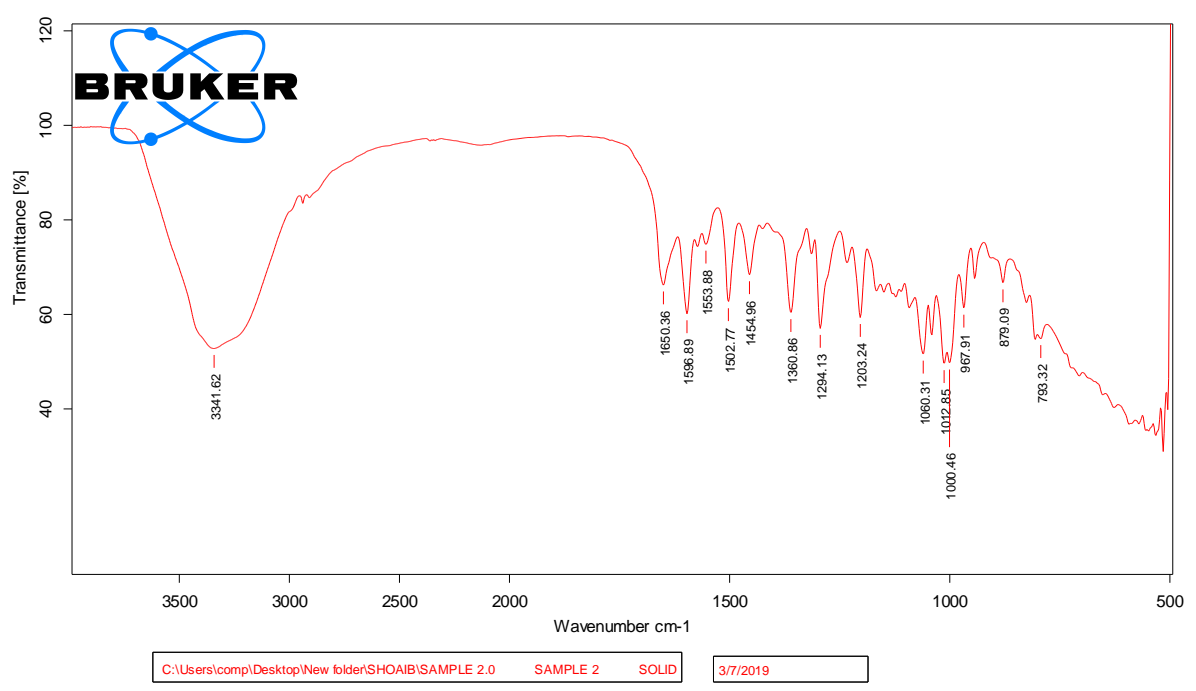

Figure 3: FTIR analysis of RCNP's.

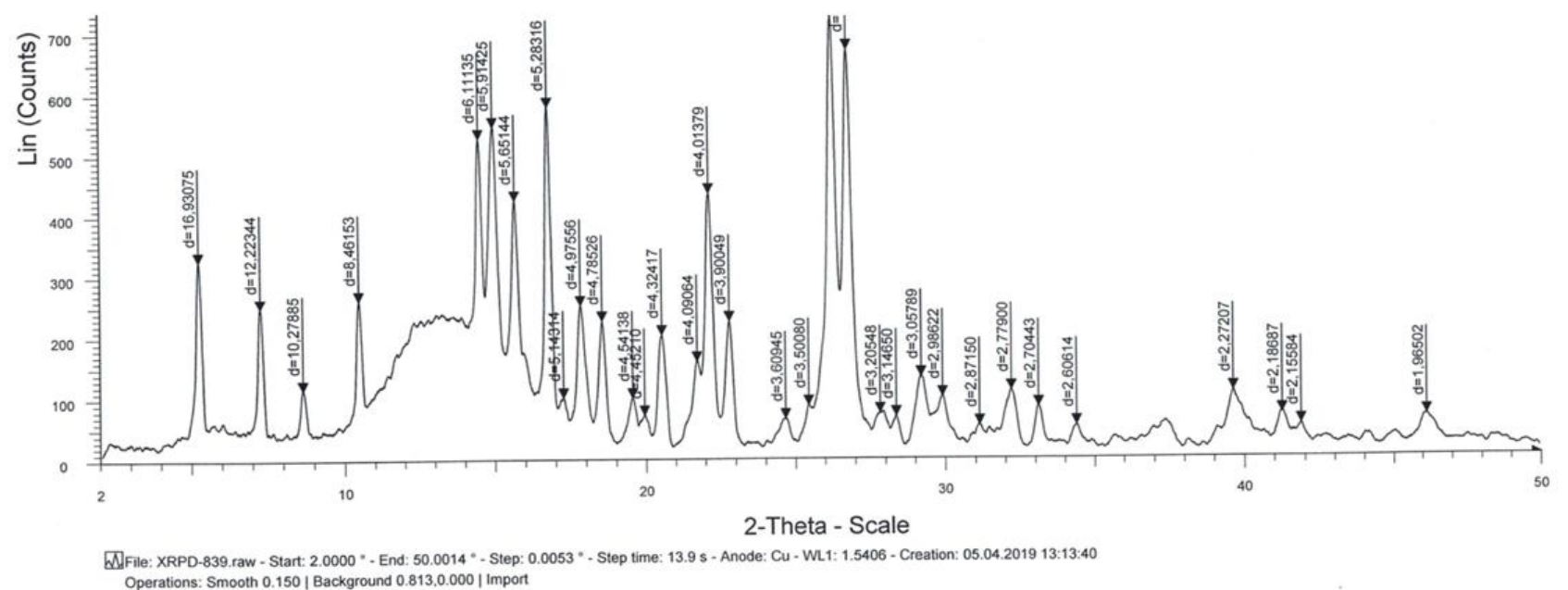

Operations: Smooth 0.150 | Background $0.813,0.000$ | Import

Figure 4: XRD pattern of RCNPs.
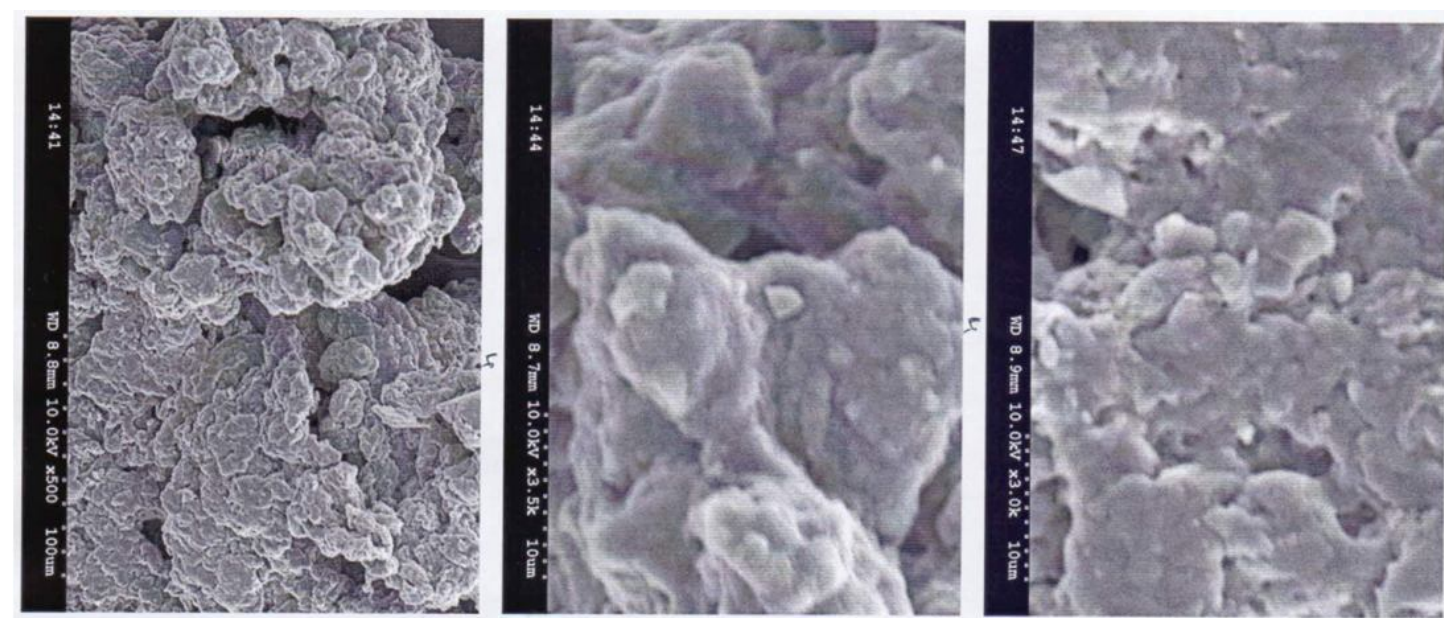

Figure 5: SEM image of RCNPs. 


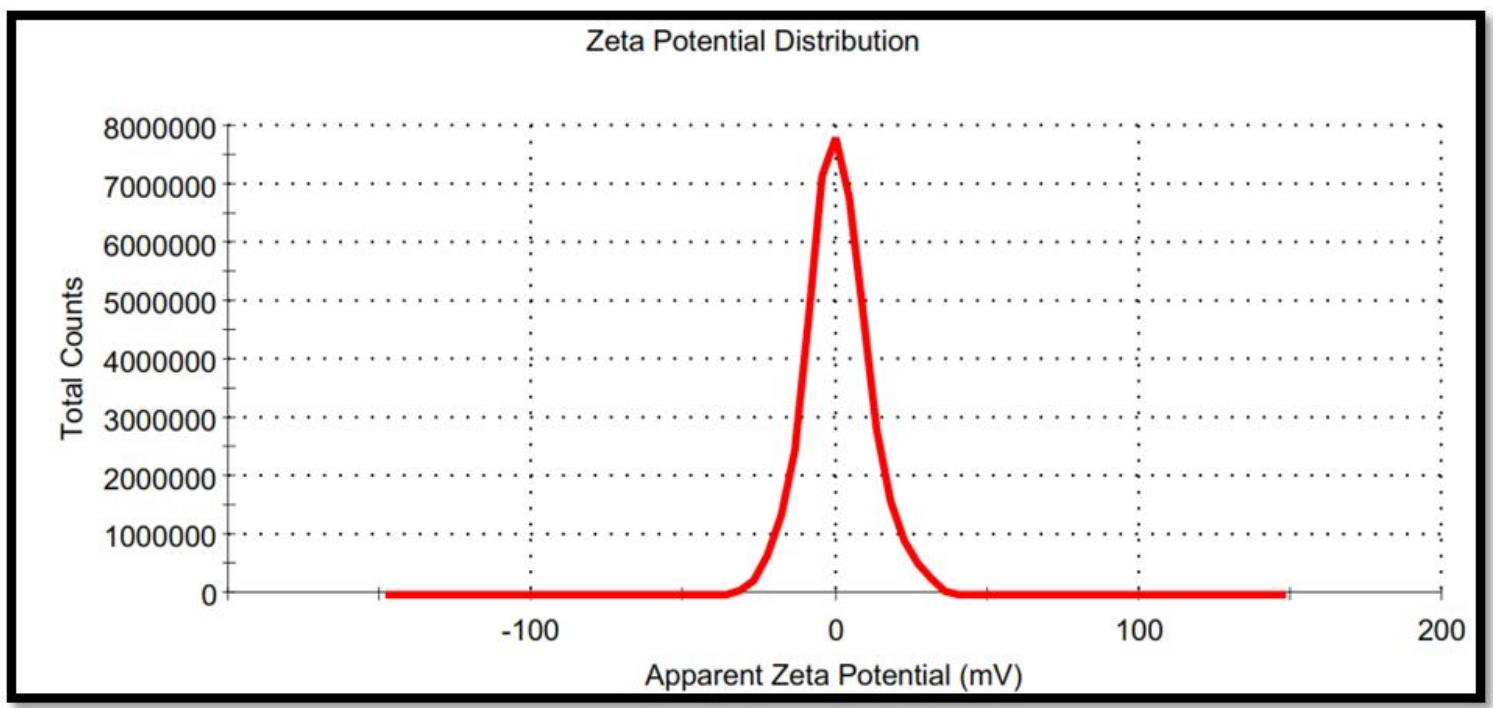

Figure 6: Zeta potential of RCNPs.

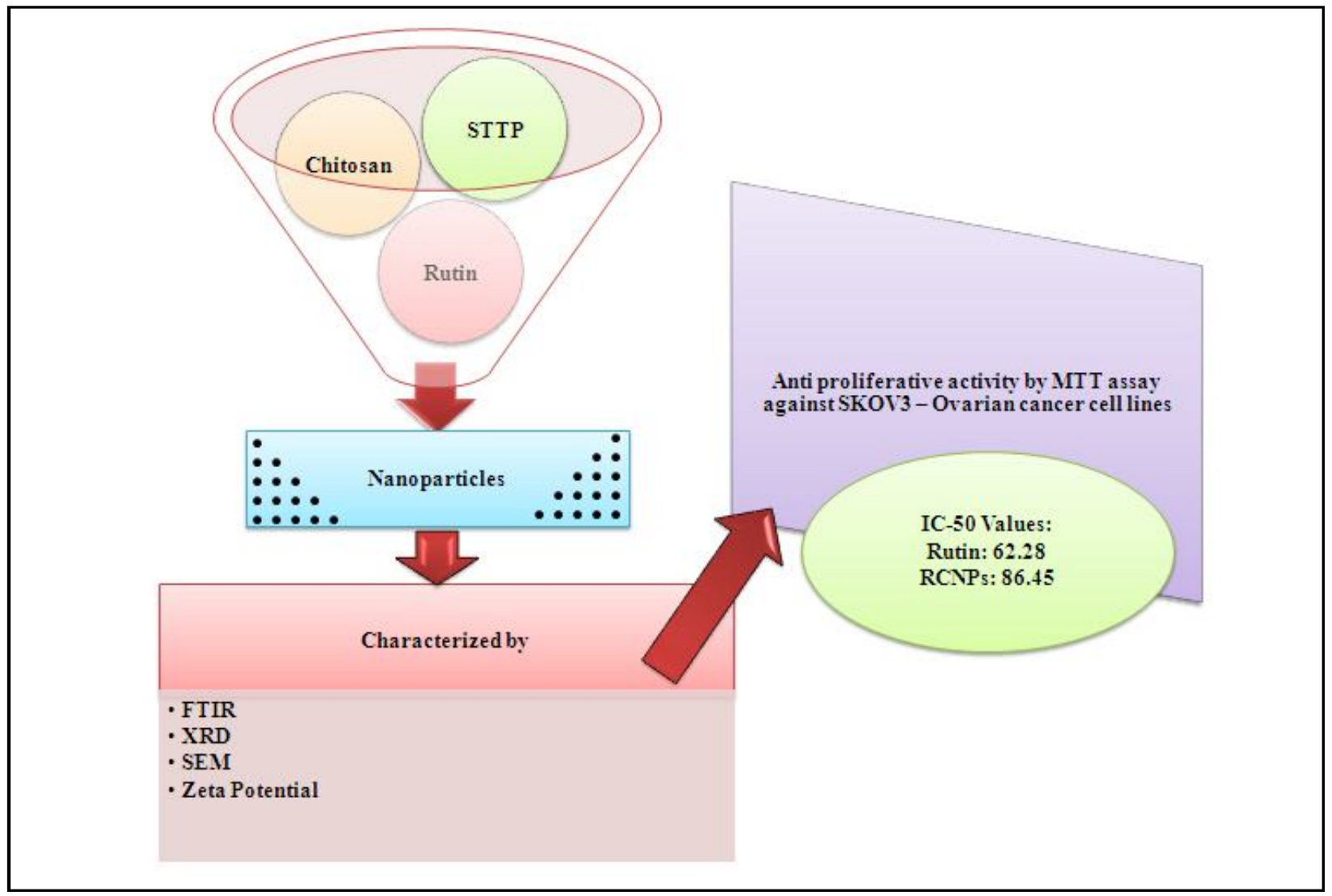

Figure 7: Graphical abstract explaining synthesis, characterization and antiproliferative activity of rutin and RCNPs.

Table 1: Antiproliferative activity of pure rutin and RCNPs

\begin{tabular}{|l|c|c|c|c|c|}
\hline Compounds & HeLa & MDAMB231 & Panc $^{-1}$ & PC3 & SKOV3 \\
\hline Pure rutin $(\mathbf{5 0} \boldsymbol{\mu M})$ & -- & -- & -- & -- & $62.28 \pm 19.42$ \\
\hline RCNP $(\mathbf{5 0} \boldsymbol{\mu M})$ & -- & -- & -- & -- & $86.45 \pm 19.46$ \\
\hline
\end{tabular}




\subsection{Antiproliferative activity of RCNPs by MTT assay}

The $\mathrm{IC}_{50}$ values against SK0V3 cell lines for rutin and RCNPs was found to be $62.28 \pm 19.42$ and $86.45 \pm 19.46$, respectively (Table 1). Thus, efficacy of rutin and RCNPs against ovarian cancer cell line is reported for the first time. However, in our study, both rutin and RCNPs have not showed any activity against HeLa, MDA - MB231, Panc ${ }^{-1}$ and PC3. Graphical abstract explaining synthesis, characterization and antiproliferative activity of rutin and RCNPs is presented in Figure 7.

\section{Discussion}

RCNPs were prepared by adding rutin to the chitosan solution. To this, chitosan solution STPP was added. After overnight stirring, above mixture is subjected to centrifugation at $8000 \mathrm{rpm}$, then the nanoparticles are separated by removing the supernatant and then washed with ethanol and stored for further studies. EE\% can be increased by optimizing the quantities of chitosan, drug and also by optimizing temperature, rotating speed, and $\mathrm{pH}$. LE\% is the actual amount of drug loaded in RCNPs. \% yield of RCNPs was found to be $31.08 \%$. These results are similar to other studies, viz., Patil and Jobanputra (2015) got $36.72 \%$ of \% yield and $32.24 \%$ of EE\% when they prepared rutin loaded chitosan nanoparticles. \% yield was less but EE\% was far better in our study. Moreover, both efficiencies and \% yield can be increased by optimizing the ratio between chitosan and STTP.

In FTIR peaks of chitosan nanoparticles $1635.50 \mathrm{~cm}^{-1}$ indicates interaction between STTP and chitosan, $1539 \mathrm{~cm}^{-1}$ indicates $-\mathrm{NH}$ bending vibration of primary amine. In case of RCNPs (Figure 3), $3341 \mathrm{~cm}^{-1}$ and $1650.50 \mathrm{~cm}^{-1}$ indicates $-\mathrm{OH}$ stretching vibration and $\mathrm{C}=\mathrm{O}$ stretching vibrations, respectively. $1454 \mathrm{~cm}^{-1}, 1203 \mathrm{~cm}^{-1}$, and $1060 \mathrm{~cm}^{-1}$ indicates $\mathrm{C}=\mathrm{C}$ vibrations, $\mathrm{P}=\mathrm{O}$ vibrations and $\mathrm{C}-\mathrm{O}-\mathrm{C}$ vibrations of rutin, respectively. This confirms loading of rutin in chitosan nanoparticles. $1596 \mathrm{~cm}^{-1}$ indicates $-\mathrm{NH}$ bending vibration of primary amine of chitosan. Our results are in conformity with the study conducted by Patil and Jobanputra (2015) where they reported -OH stretching vibration is due to a broad peak at 3498 $\mathrm{cm}^{-1}$, interaction between STTP and chitosan is due to a peak at $1637 \mathrm{~cm}^{-1}$, confirmation of loading rutin is indicated by C-O-C vibrations of rutin which showed a peak at $1064 \mathrm{~cm}^{-1}$ (Ashwini et al., 2015). Diffractogram showed many XRD peaks below $30^{\circ}$ which indicates semi crystalline nature of chitosan. Size of RCNPs was found to be $22.31 \mathrm{~nm}$ to $42.32 \mathrm{~nm}$ with an average size of $32.15 \mathrm{~nm}$ by using Debye-Scherrer's equation. Similar results were obtained by Khan et al. (2016).

According to SEM study, porous morphology of RCNPs is reported. This facilitates in swelling and rapid release of drug. Surface morphology depicted in our study is in accordance with SEM results of Cahyono et al. (2017). Low cross linking densities of nanoparticles is credited due to porous, rough, loose and open surface morphology (Bhumkar and Pokharkar, 2006). Results of zeta potential measurement showed reduced stability of rutin loaded chitosan nanoparticles. This is due to various factors such as types of biopolymers and their quantity, ionic strength, and $\mathrm{pH}$ of the solution. Value near to zero may be due to -vely charged groups of rutin (Ashwini et al., 2015). RCNPs are effective against SKOV3 cells. Rutin is a citrus flavonoid found in many plants. Long term and high intake of flavonoids will decrease the incidence of ovarian cancer (Evans, 2011). Results indicated that RCNPs are more effective than rutin. This increased activity of rutin loaded chitosan nanoparticles is due to targeted delivery of nanoparticles. Moreover, both pure rutin and RCNPs are not active against other cell lines, viz., HeLa, MDAMB231, Panc ${ }^{-1}$ and PC3.

\section{Conclusion}

Current investigation portrays easy method for incorporation of insoluble phytoconstituent rutin in chitosan nanoparticles. Synthesized RCNPs are stable and water soluble. Moreover, successful encapsulation of rutin in nanoparticles improves bioavailability of rutin and their by increasing its therapeutic effect. Obtained results more prominently authenticate the effectiveness of rutin loaded chitosan nanoparticles; this may be attributed to increased antiproliferative action, intracellular accumulation and cellular uptake. Thus, chitosan loaded rutin nanoparticles provide a proficient tool for encapsulation and delivery of rutin by increasing its stability and water solubility for making it an efficient treatment option for cancer. Further studies should be carried out to screen anticancer potential by using higher conc. of RCNPs against other cell lines (MDAMB231, Panc-1, HeLa and PC3). Study also directs the conduct of in vivo studies of RCNPs against ovarian cancer.

\section{Conflict of interest}

The authors declare that there are no conflicts of interest relevant to this article.

\section{References}

Ahmad, N.; Ahmad, R.; Naqvi, A.A.; Alam, A.; Ashafaq, MD.; Samim, MD.; Iqbal, Z. and Ahmad, F.J. (2016). Rutin-encapsulated chitosan nanoparticles targeted to the brain in the treatment of Cerebral Ischemia. Int. J. Biol. Macromol., 91:640-655.

Alonso-Castro, A.J.; Dominguez, F. and Garcia-Carranca, A. (2013). Rutin exerts antitumor effects on nude mice bearing SW480 tumor. Arch. Med. Res., 44(5):346-351.

Anitha,A.; Deepagan, V.G.; Divya Rani, V.V.; Menon, D.; Nair, S.V. and Jayakumar, R. (2011). Preparation, characterization, in vitro drug release and biological studies of curcumin loaded dextran sulphate-chitosan nanoparticles. Carbohyd. Polym., 84(3):1158-1164.

Annapurna, A.; Reddy, C.S.; Akondi, R.B. and Rao, S.R. (2009). Cardioprotective actions of two bioûavonoids, quercetin and rutin, in experimental myocardial infarction in both normal and streptozotocin-induced type I diabetic rats. J. Pharm. Pharmacol., 61(10): 1365-1374

Araujo, J.R.; Goncalves, P. and Martel F. (2011). Chemopreventive effect of dietary polyphenols in colorectal cancer cell lines. Nutr. Res., 31(2):77-87.

Asad Khan, M.D.; Zafaryab, M.D.; Mehdi, S.H.; Ahmad, I. and Rizvi, M.A.M. (2016). Characterization and anti-proliferative activity of curcumin loaded chitosan nanoparticles in cervical cancer. Int. J. Biol. Macromol., 93:242-253.

Ashwini, G.P.; Harshada, R.B.; Mahesh, P.M.; Prashant, KD. and Pravin, O.P. (2015). Rutin-chitosan nanoparticles: Fabrication, characterization and application in dental disorders. Polymer-Plastics Technology and Engineering, 54(2):202-208.

Balachandran, P. and Govindarajan, R. (2005). Cancer: An ayurvedic perspective. Pharmacol. Res., 51:19-30.

Bhumkar, D.R. and Pokharkar, V.B. (2006). Studies on effect of pH on Crosslinking of chitosan with sodium tripolyphosphate: A technical note, AAPS Pharm. Sci. Tech., 72:2-7. 
Cahyono, B.; Sestri Bela Pratiwi, S.B.; Hadiyanto. and Suzery, M. (2017). Encapsulation rutin with chitosan-NATPP using coaservation Method. Reaktor., 17(4):215-220.

Chen, C.Y.; Li, H.; Yuan, Y.N.; Dai, H.Q. and Yang, B. (2013). Antioxidant activity and components of a traditional Chinese medicine formula consisting of Crataegus pinnatifida and Salvia miltiorrhiza. BMC Complement. Altern. Med., 523:99-102.

Dodane, V. and Vilivalam, D. (1998). Pharmaceutical applications of chitosan. Pharm. Sci.Technol. Today, 1(6):246-253.

Evans, K. (2011). Flavonoids in fruits, vegetables and nuts dramatically lower cancer rates. Tags: cancer, flavonoids, health news, September.

Harborne, J.B. (1986). Nature, distribution and function of plant ûavonoids. Prog. Clin. Biol. Res., 213:15-24.

Hassanpour, S.H. and Dehghani, M. (2017). Review of cancer from perspective of molecular. Journal of Cancer Research and Practice, 4:127-129.

Hooresfand, Z.; Ghanbarzadeh, S. and Hamishehkar, H. (2015). Preparation and characterization of rutin-loaded nanophytosomes. Pharmaceutical Sciences, 21(1):145-151

Imad Uddin, M.D. and Veeresh, B. (2020). Systematic review on screening the role of chemosensitizer or synergistic drug and doxorubicin as dual drug loaded nanoparticle in overcoming multidrug resistant breast cancer. Ann. Phytomed., 9(2):1-12.

Imad Uddin, M.D.; Kavya, G.; Soundarya, G.; Ropa, G. and Sridhar, C.H. (2018) Antidiabetic activity of silver nanoparticles synthesized from ashwagandha root aqueous extract. Asian Journal of Pharmaceutical Education and Research, 7(2):45-49.

Imad Uddin, M.D.; Rachana, N.; Suraj, N.; Naveena, N. and Mounica P. (2019). Screening anticancer activity of colchicine loaded chitosan nanoparticles. Pharmacophore, 10(2):37-42.

Khan, J.; Alexander, A.; Ajazuddin.; Saraf, S. and Saraf, S. (2013). Recent advances and future prospects of phytophospholipid complexation technique for improving pharmacokinetic profile of plant actives. J. Control Release, 168:50-60.

Kiran, D.; Khan, M.A.; Sharma, Y.D.; Moinuddin. and Alam, K. (2010). Physicochemical studies on peroxynitrite-modiûed H3 histone. Intl. J. Biol. Macromol., 46(1):20-26.

Li, Z.; Jiang, H.; Xu, C. and Gu, L. (2015). A review: Using nanoparticles to enhance absorption and bioavailability of phenolic phytochemicals. Food Hydrocoll., 43:153-164.

Lin,J.P.; Yang, J.S.; Lin, J.J.; Lai, K.C.; Lu, H.F.; Ma, C.Y.; Sai-Chuen, Wu.R.; Wu, K.C.; Chueh, F.S.; Gibson Wood, W. and Chung, J.G. (2012). Rutin inhibits human leukemia tumor growth in a murine xenograft model in vivo. Environ. Toxicol., 27(8):480-484.

Machado, D.G.; Bettio, L.E.; Cunha, M.P.; Santos, A.R.; Pizzolatti, M.G.; Brighente, I.M. and Rodrigues, A.L. (2008). Antidepressant-like effect of rutin isolated from the ethanolic extract from Schinus molle L. in mice: Evidence for the involvement of the serotonergic and noradrenergic systems. Eur. J. Pharmacol., 587(1-3): 163-168

Mariyappan, S.; Pichaiyan, V.; Ramalingam, S. and Saravanan, R. (2018). A review on the role of phytoconstituents in cancer cells. Journal of Global Pharma. Technology, 10(2):1-10.

Mauludin, R.; Muller, R.H. and Keck, C.M. (2009). Development of an oral rutin nanocrystal formulation. Int. J. Pharmaceut., 370:202-209.
Mouria, M.; Gukovskaya, A.S.; Jung, Y.; Buechler, P.; Hines, O.J.; Reber, H.A. and Pandol, S.J. (2002). Food-derived polyphenols inhibit pancreatic cancer growth through mitochondrial cytochrome $\mathrm{C}$ release and apoptosis. Int. J. Cancer, 98(5):761-769.

Nieoczym, D.; Socala, K.; Raszewski, G. and Wlaz, P. (2014). Effect of quercetin and rutin in some acute seizure models in mice. Prog. Neuropsychopharmacol. Biol. Psychiatry, 54:50-58.

Patil, A.G. and Jobanputra, A.H. (2015). Rutin chitosan nanoparticles: fabrication, characterization and application in dental disorders. Polymer-Plastics Technology and Engineering, 54(2):202-208, doi: $10.1080 / 03602559.2014 .935425$

Patil, J.S.; Kamalapur, M.V.; Marapur, S.C. and Kadam, D.V. (2010). Ionotropic gelation and polyelectrolyte complexation: the novel techniques to design hydrogel particulate sustained, modulated drug delivery system: A review. Digest Journal of Nanomaterials and Biostructures, 5(1):241-248.

Pu, F.; Mishima, K.; Irie, K.; Motohashi, K.; Tanaka, Y.; Orito, K.; Egawa, T.; Kitamura, Y.; Egashira, N.; Iwasaki, K. and Fujiwara, M. (2007). Neuroprotective effects of quercetin and rutin on spatial memory impairment in an 8-arm radial maze task and neuronal death induced by repeated cerebral ischemia in rats. J. Pharmacol. Sci., 104:329-334.

Pugazhendhi, A.; Shafreen, R.B.; Devi, K.P. and Suganthy, N. (2018). Assessment of antioxidant, anticholinesterase and antiamyloidogenic effect of Terminalia chebula, Terminalia arjuna and its bioactive constituent 7-Methyl gallic acid: An in vitro and in silico studies. J. Mol. Liq., 257:69-81.

Qian, F.; Cui, F.; Ding, J.; Tang, C. and Yin, C. (2006). Chitosan graft copolymer nanoparticles for oral protein drug delivery: Preparation and characterization. Biomacromolecules, 7(10):2722-2727.

Ravi Kumar, M.N.V. (2001). A review of chitin and chitosan applications. React. Funct. Polym., 46:1-27.

Rylski, M.; Duriasz-Rowinska, H. and Rewerski, W. (1979). The analgesic action of some flavonoids in the hot plate test. Acta Physiol. Pol., 30(3):385-388

Scambia, G.; Ranelletti, F.O.; Benedetti, Panici, P.; Bonanno, G.; De Vincenzo, R.; Piantelli, M. and Mancuso, S. (1990). Synergistic antiproliferative activity of quercetin and cisplatin on ovarian cancer cell growth. Anticancer Drugs, 1(1):45-48

Selvaraj, G.; Kaliamurthi, S.; Thirungnasambandam, R.; Vivekanandan, L and Balasubramanian, T. (2014). Antinociceptive effect in mice of thillai flavonoid rutin. Biomed. Environ. Sci., 27(4):295-299.

Sepahvand, R.; Delfan, B.; Ghanbarzadeh, S.; Rashidipour, M.; Veiskarami, G.H. and GhasemianYadegari, J. (2014). Chemical composition, antioxidant activity and antibacterial effect of essential oil of the aerial parts of Salvia sclareoides. Asian Pac. J. Trop. Med., 7:S491S496.

Shaûei, S.S.; Solati-Hashjin, M.; Samadikuchaksaraei, A.; Kalantarinejad, R.; Asadi-Eydivand, M. and Abu Osman, N.A. (2015). Epigallocatechin gallate/layered double hydroxide nanohybrids: Preparation, characterization, and in vitro antitumor study. PLoS ONE, 10(8): $1-18$.

Shanmuganathan, R.; Edison, T.N.J.I.; LewisOscar, F.; Ponnuchamy, K.; Shanmugam, S. and Pugazhendhi, A. (2019). Chitosan nanopolymers: An overview of drug delivery against cancer, Int. J. Biol. Macromol., 130:727-736. 
Sharma $P$ and Garg S. (2010). Pure drug and polymer based nanotechnologies for the improved solubility, stability, bioavailability and targeting of anti-HIV drugs. Adv. Drug Delivery Rev., 62:491-502

Shihabul Islam, M.D.; Sifat Rahi, M.D.; Arif Jahangir, C.; Habibur Rahman, M.D.; Jerin, I.; Amin, R.; Kazi, M.D.; Hoque, F. and Abu Reza, M.D. (2018). In Vivo anticancer activity of Basella alba leaf and seed extracts against Ehrlich's Ascites Carcinoma (EAC) cell line. Evid-Based Compl. Alt., 2018:1-11.
Shu, X.Z. and Zhu, K.J. (2002). Controlled drug release properties of ionically cross-linked Chitosan beads: The influence of anion structure. Int. J. Pharm., 233(1-2):217-225.

Thomas, V.Y.; Mohan, M.B. and Sreedhar, S.K.B. (2009). Fabrication, characterization of chitosan/nanosilver film and its potential antibacterial application. J. Biomater. Sci. A Polym. Ed, 20(14):2 129-2144.

Wang, Z.L (2000), A textbook of characterization of nanophase materials. Wiley-VCH, Germany, First Edition.

M.D. Imad Uddin, K. Saivani, K.V. Akhil, K. Nandini, K. Sandhya and Faizan Sayeed (2021). Synthesis, characterization and anticancer activity of rutin loaded chitosan nanoparticles. J. Phytonanotech. Pharmaceut. Sci., 1(1):16-23. http://dx.doi.org/10.21276/jpps.2021.1.1.5 